\title{
Book review - Lesson study-based teacher education: the potential of the Japanese approach in global settings
}

Lesson study-based teacher education: the potential of the Japanese approach in global settings

Kim et al.

2021

p. 219

The book Lesson Study-Based Teacher Education: The Potential of the Japanese Approach in Global Settings is edited by Jongsung Kim, Nariakira Yoshida, Shotaro Iwata and Hiromi Kawaguchi. Published in 2021 and spanning 219 pages, it is the newest addition to the WALS-Routledge Lesson Study Series, which aims to provide an international platform for Lesson Study research from diverse global and regional settings. This is exactly what the editors - a group of experienced researchers from the Hiroshima University in Japan with extensive expertise on the subject - offer in their book. It is an inside perspective on Lesson Study in Japanese teacher education, with all its various forms, opportunities and limitations. Their voices from Japan, the country in which Lesson Study originated and from where it spread around the globe in the 1980s, are complemented by perspectives from researchers in Europe, the US, South America and Africa, who have adapted Lesson Study to their national contexts. Organized into four parts, the book meets the challenge of bridging the divide between the different global conceptualizations of this approach to professional development.

The book opens with Kawaguchi and Iwata outlining the starting point and aim of the book. Lesson Study in Japan is much more than a fixed method of professional development; it takes many forms and shapes that sometimes clash with ways in which it is understood abroad. The aim of the book is to provide a bigger picture by showing the readers "two mirrors": Lesson Study in the Japanese Jugyou Kenkkyuu-based teacher education on the one hand, and, on the other, case studies of authentic regional Lesson Study adaptions rooted in their own national, political and socio-cultural contexts. In doing so, the book hopes to encourage its readers to reflect on the potentials of the method in their own settings.

The primary themes of the books revolve therefore around Lesson Study's many faces and how transcultural comparisons can help us bridge conceptual differences. Fittingly, the first part of the book looks at Lesson Study both in and outside of Japan. In chapter two, Kim explains that the Japanese reading of the term Lesson Study includes all activities that help teachers develop their instructions and improve student learning in the classroom. This broad conceptualization developed out of the country's unique pedogeological history and is shaped by the fact that Lesson Study has been, and still is, implemented mainly as a top-down approach in Japan. As a result, Lesson Study culture is systemically reproduced through Japan's teacher education, which has led to the emergence of a Lesson Study "grammar" (p. 19). By this, Kim means a shared common knowledge about the procedures of Lesson Study that teachers and teacher educators can draw on. Outside of Japan, where Lesson Study often emerges as a grass-roots approach, this mutual understanding is still being negotiated and developed by its stakeholders, to various degrees of success. Yet, Kim warns us to not romanticize the culture of Lesson Study

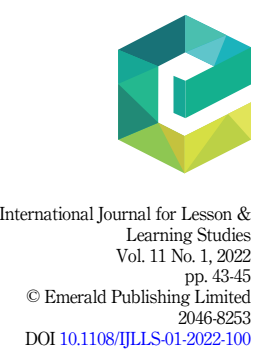


IJLLS 11,1

in Japan and hints at the "side-effects" of this top-down approach, which are further developed in later chapters. Chapter three, written by Yoshida, Matsuda and Miyamoto, demonstrates the variability and global popularity of Lesson Study through a mass-scaled analysis of almost 900 research articles. Synthesizing the manifold research objectives and foci investigated in current research, they provide a thorough overview of the landscape of Lesson Study research worldwide.

The second part of the book, consisting of four chapters, narrows in on different aspects of Lesson Study-based teacher education in Japan. In chapter four, Kawaguchi and Watanabe describe the historical roots of Lesson Study's emergence in Japanese pre-service teacher education and outline current perceptions of the method in a case study based on Japanese teacher educators. Chapter five, written by Mase, explores how Lesson Study in the teaching practicum allows students to gradually develop their role as future teachers and teacher researchers. Iwata and Hamamoto center their chapter on a "new style" of Lesson Study, called COOLS. In order to tackle problems in the way that Lesson Study is currently implemented, which they link in part to Japan's top-down approach, the authors suggest a short-term and more intense framework for teachers. They illustrate the COOLS approach using a case study of a physical education lesson. In the last chapter in this section, Miyoshi and Komatsu shift the conversation to in-service teachers by contrasting Japanese Lesson Study in different settings: the formal and public setting versus the private sector and nongovernmental educational research organizations.

The third part of the book, entitled The potentials and challenges of Lesson Study-based teacher education globally, spans four chapters that illustrate how countries outside of Japan have interpreted Lesson Study for their own needs. A Norwegian perspective is offered by Smith, who frames Lesson Study as a research methodology similar to Self-Study that can prove useful for the continuing professional development of, not only teachers, but also teacher educators. In chapter nine, McArthur Harris et al. report on a case study conducted in rural Michigan in the USA and share the lessons they learned. Chapter ten, by Hallitzky et al., summarizes types of Lesson Study in German-speaking countries and discusses the importance of classroom observations to the researchers' understanding of the method. Saito and Shiraishi complete this part of the book with a comparative analysis of Lesson Study implementations in Peru and Uganda accompanied by Japanese experts. They echo the theme of the book by identifying Lesson Study as a "bridge between Japan and developing countries" (p. 178).

The fourth part comprises two chapters that widen the book's perspective, taking a birdeye's view on Lesson Study's potentials. In chapter twelve, Yoshida and colleagues consider the impact that different stakeholders might have on Lesson Study, and vice versa. We might think of Lesson Study as a method used only by teachers and pre-service teachers. But, as the authors argue, Lesson Study involves stakeholders beyond educational personnel, such as school nurses, social workers, parents and the students themselves. Framing Lesson Study as more than merely a research method, they invite the reader to reflect on it as a gateway to community-based educational practices.

Kim concludes the book by looking ahead, critically discussing Lesson Study's to date "underexamined potential" as a democratic method of teacher professional development (p. 208). Considering aspects such as teacher agency, democracy of knowledge, as well as collaboration and community, he describes how Lesson Study can serve as a platform for collegial and collaborative professionalism that empowers teachers in their role as educational agents. He closes by returning to the book's primary themes that Lesson Study has the potential to be more than just a research methodology, and that a global perspective can help us understand how to best tap into and maximize this potential.

The book presents a timely perspective on the many conceptualizations of Lesson Study in and outside of Japan. In many ways, the content complements current debates on Lesson 
Study's variability, the difficulty of translating the method into non-Japanese contexts and the need for a more contextualized approach when investigating the method's impact. One of the key strengths of the book are the insights shared by Japanese researchers in its second section. The four chapters provide a well-rounded picture of Lesson Study's history and the editors' experience with the method in the Japanese setting - a subject that tends to get short shrift in international Lesson Study research. As Kim notes, empirical research on Lesson Study in Japan is scarce, mainly because the method's long tradition is considered sufficient proof of its effectiveness (p. 24). The combination of descriptive knowledge of the method and the results from Lesson Study case studies in Japan make this book a much-needed contribution to the field.

Arguably, one of the most compelling insights of the book is Kim's description of the "grammar" of Lesson Study, which is used throughout Japan's teacher education system. Outside of Japan, this common understanding of Lesson Study between teachers, educators, researchers and policy makers is not a given-but needs to be reinvented, translated and practiced in regional contexts. It would have been interesting if the authors of subsequent chapters had developed this point alongside their international perspectives. Given the research community's rising interest in Lesson Study as an internationally practiced policy, the debate on what role such a shared "grammar" between stakeholders might play in the future in the success of establishing sustainable national Lesson Study cultures outside of Japan seems to be an important one.

On a different note, the book's title Lesson Study-Based Teacher Education could be considered slightly misleading. In a narrow sense, the title can be understood as referring to the education of pre-service teachers, rather than the continuing education of all teaching staff. The title's intended meaning is clarified in the introduction, with Kawaguchi and Iwata defining Lesson Study-based teacher education as including several diverse practices carried out by both pre- and in-service teachers. Nevertheless, readers unfamiliar with the writers' context might miss the subtlety of this reading.

To sum up, the book marks another great contribution to the WALS Series and is definitely worth a read both for those using Lesson Study and those researching it. The former will find practice-based tips on how to grapple with various problems when implementing the method in a new setting. The latter will find descriptive knowledge and some theorization of the approach, paired with an impetus to reflect on how current national and regional translations of Lesson Study can benefit from transcultural perspectives.

Klara Kager

Empirical Intervention and Instruction Research, University of Potsdam, Potsdam, Germany 